DOT/FAA/AM-06/8

Office of Aerospace Medicine

Washington, DC 20591

\title{
Human Factors Implications of Unmanned Aircraft Accidents: Flight-Control Problems
}

Kevin W. Williams

Civil Aerospace Medical Institute Federal Aviation Administration

Oklahoma City, OK 73125

April 2006

Final Report 


\section{NOTICE}

This document is disseminated under the sponsorship of the U.S. Department of Transportation in the interest of information exchange. The United States Government assumes no liability for the contents thereof.

This publication and all Office of Aerospace Medicine technical reports are available in full-text from the Civil Aerospace Medical Institute's publications Web site: www.faa.gov/library/reports/medical/oamtechreports/index.cfm 



\section{Human Factors Implications of Unmanned Aircraft AcCidents: Flight-Control Problems}

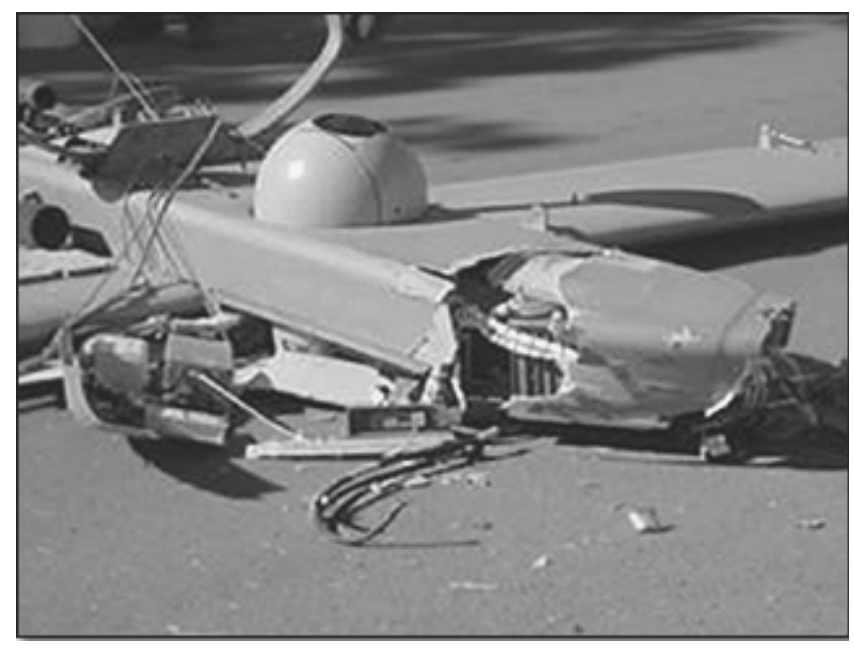

\section{INTRODUCTION}

Unmanned aircraft (UA) have suffered a disproportionately large number of mishaps relative to manned aircraft (Williams, 2004). In 1996, the Air Force Scientific Advisory Board (AFSAB) identified the human/system interface as the greatest deficiency in current UA designs (Worch et al., 1996). A recent review of accident statistics for military UA lends support to this statement. However, the particular interface deficiencies responsible for most accidents differed across the various systems (Williams, 2004).

In reviewing accident data for UA, two approaches can be used. The first is to focus on a particular aircraft system, noting the deficiencies in the interface design for that system that led to individual accidents. The second is to look at accidents across systems, focusing on categories of mishaps that occur across a variety of systems. The first approach can result in specific design changes for a particular system. The second can reveal basic human factors issues that apply across a variety of systems. In this chapter, we will use the second approach and look at UA accidents across a variety of systems and focus on categories of accidents involving flight control. The success or failure of UA will at least in part be determined by how easily they can be flown. Once the pilot has been separated from the aircraft, designers are faced with the basic problem of how to control the aircraft during the flight.

Three flight-control categories have been selected for review. The first category involves the use of an external pilot (EP) to control the flight of the aircraft. Basically, an EP is a pilot that controls the aircraft using direct line-of-sight, similarly to radio-control aircraft hobbyists. Flight using an EP represents the most basic solution to the problem of separating the pilot from the aircraft while still enabling the pilot to monitor the location and attitude of the aircraft. Pilot perspective is changed from an egocentric to an exocentric point of view. The problems that this change creates will be discussed later.

The second category concerns the transfer of control during flight. While transfer of control can occur within a manned cockpit, it does not entail the difficulty or variety of methods encountered with UA systems. Transfer of control can occur in a number of different ways, as will be discussed below. In addition, the protocol for transferring control from one pilot to another can differ radically from system to system. Almost every current system has encountered mishaps associated with transfer of control. We will review these problems and look at potential solutions for them.

The third flight-control category is the automation of flight control. Perhaps because the pilot has been removed from the aircraft, there seems to be an unspoken goal of UA designers to remove the pilot altogether from the system. This involves automating all of the flight control responsibilities. One of the latest military UA, the Global Hawk, is totally automated from initial taxi and takeoff to landing. However, the implementation of automation has not prevented the occurrence of mishaps attributed specifically to the automation. It will be useful to review some of these mishaps for ideas on how to improve these systems. 
Rather than just a statistical summary of accident data related to UA, which can be found elsewhere (Manning, Rash, LeDuc, Nobak, \& McKeon, 2004; Williams, 2004), this chapter will include reviews of a number of specific accidents related to the categories listed above. The intent is to suggest possible interventions to prevent such accidents from occurring.

\section{External Piloting}

The most basic solution for monitoring the position and attitude of an UA is through direct line-of-sight. A pilot that maintains direct line-of-sight with the aircraft is usually referred to as the external pilot (EP), as opposed to an internal pilot (IP) that obtains position and attitude information electronically. Maintaining visual contact with the UA, the EP can control the aircraft using a hand-held radio-control box. Many of these control boxes are similar to those used by radio-controlled aircraft hobbyists and provide direct control of the flight surfaces of the aircraft through the use of joysticks on the box (see Figure 1). Very little automation is involved in the use of such boxes, which control the flight surfaces of the aircraft.

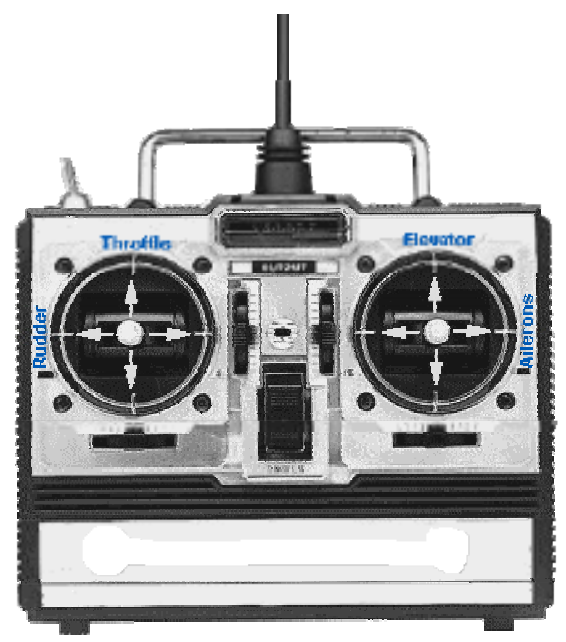

Figure 1: Radio flight-control box.

For those systems that require an EP, statistics show that controlling the UA during landing is a difficult problem (Gawron, 1998; Williams, 2004). For example, with the Hunter system flown by the U.S. Army, $47 \%$ of the human-factors-related accidents occurred while landing the aircraft. An additional $20 \%$ of the accidents involved an error by the EP during takeoff(Williams, 2004). Likewise the Pioneer, which also uses an EP, experiences a proportionately large number of accidents during landing. A recent analysis of accident data for the Pioneer revealed that the largest percentage of human factors accidents $(68 \%)$ was associated with difficulties experienced by the EP while landing the aircraft (Williams, 2004).
Probably the main reason for EP control difficulties is that there is an inconsistent mapping between the movement of the joystick and the response of the aircraft. The failure of a flight control to perform consistently (from the perspective of the pilot) is a violation of the human factors principle of motion compatibility (McCarley \& Wickens, 2005; Wickens \& Hollands, 2000). For example, when the aircraft is approaching the EP, the control inputs to maneuver the aircraft left and right are opposite what they would be when the aircraft is moving away from the EP. This inconsistent mapping problem is present for any UA operated using a traditional control box via visual contact.

Many current systems have eliminated the need for an external pilot either by automating the takeoff and landing process or by providing adequate visual, positional, and attitudinal information and control to the internal pilot to accomplish these tasks. Another solution is to make improvements to the control interface for the external pilot. Quigley, Goodrich, and Beard (2004) designed and tested a variety of control interfaces for improving the performance of the external pilot. These interfaces included a direct manipulation interface that presents a fixed-horizon, wing-view representation from the viewpoint of an observer behind the aircraft, a voicecontrolled interface, and a physical-icon interface that is basically a hand-held model of the aircraft that, when manipulated, sends control signals to the aircraft that mimic the attitude of the model.

Each of the interfaces provided some benefit to the EP, but each also had drawbacks. The physical icon interface had the fastest response time but did not resolve the issue of inconsistent mapping. The direct manipulation interface provided consistent mapping of the controls but required frequent visual accommodation adjustments between the interface and the aircraft. Finally, the voice interface resolved the mapping issue, as long as the commands were world-centered (e.g., "go north"), but was not as reliable or responsive as the other interfaces.

\section{Transfer of Control}

One of the activities unique to remotely piloted aircraft is the transfer of control from one controlling system to another. Transfer of control is usually required in UA at some point during the flight because of the limited range of the control station and/or stationary pilot. This transfer can occur in one of several ways. Control can be transferred from an external pilot to an internal pilot, from an internal pilot in one ground control station to a pilot in a second ground control station, and from one side of a ground control station to a set of duplicate controls within the same station. In addition, transfer of control during a 
flight can occur from one pilot to another, analogous to a crew change in a manned aircraft. However, even this control transfer is different in a remotely piloted aircraft because the replacement crew does not have to have been present in the control area during the flight.

The difficulty in the transfer of control is demonstrated by the fact that problems with control transfer occur in almost every UA system. It will be informative to review various mishaps involving the transfer of control in different systems to see if there are any constants across these mishaps.

Two mishaps involving the Army's Hunter system were related to the transfer of control of the aircraft (U.S. Army, 2004). In the first mishap, a maintenance crewman turned off the autopilot capability of the aircraft during routine maintenance of the aircraft but inadvertently failed to restore the autopilot functionality prior to returning the aircraft to flight status. The aircraft took off under the control of the EP who did not use the autopilot and was thus unaware that it was nonfunctional. The mishap occurred after control of the aircraft was handed off from the EP to the IP. The IP is usually given control of the aircraft with the autopilot functioning since the primary means of control by the IP is through the use of knobs and dials for setting the aircraft heading, airspeed, and altitude. Because the IP was not expecting a nonfunctional autopilot, he failed to notice that the aircraft was descending and was unable to recover the aircraft before it crashed.
In the second Hunter mishap, control of the aircraft was being transferred from one EP to another during training. The EP receiving control neglected to complete all control box checks and failed to notice that one of the switches on the box was in the wrong position (Williams, 2004).

In the case of a U.S. Army Shadow system, two aircraft were damaged during a single mission. The first was damaged due to a failure of the automated landing system. After the accident, the ground control station (GCS) crew issued a command to the damaged aircraft to kill its engine, but because of damage to the antenna the command was not received. That same GCS was then tasked with controlling a second Shadow on an approach. Unfortunately, after taking control of the second Shadow, the aircraft received the "engine kill" command that was still waiting for an acknowledgment from the GCS software, causing the second Shadow to also crash. This accident was classified as both a procedural error (because the crew failed to follow all checklist items prior to the transfer of control of the second aircraft) and a display design problem (because there was not a clear indication to the crew of the status of the "engine kill" command that had been issued; Williams, 2004).

A more recent crash was that of a Helios UA in June 2003. The Helios (Figure 2) is intended to fly for extended lengths of time at very high altitudes. During a flight test of the Helios in June 2003, the aircraft flew into turbulence that exceeded the maximum capability of

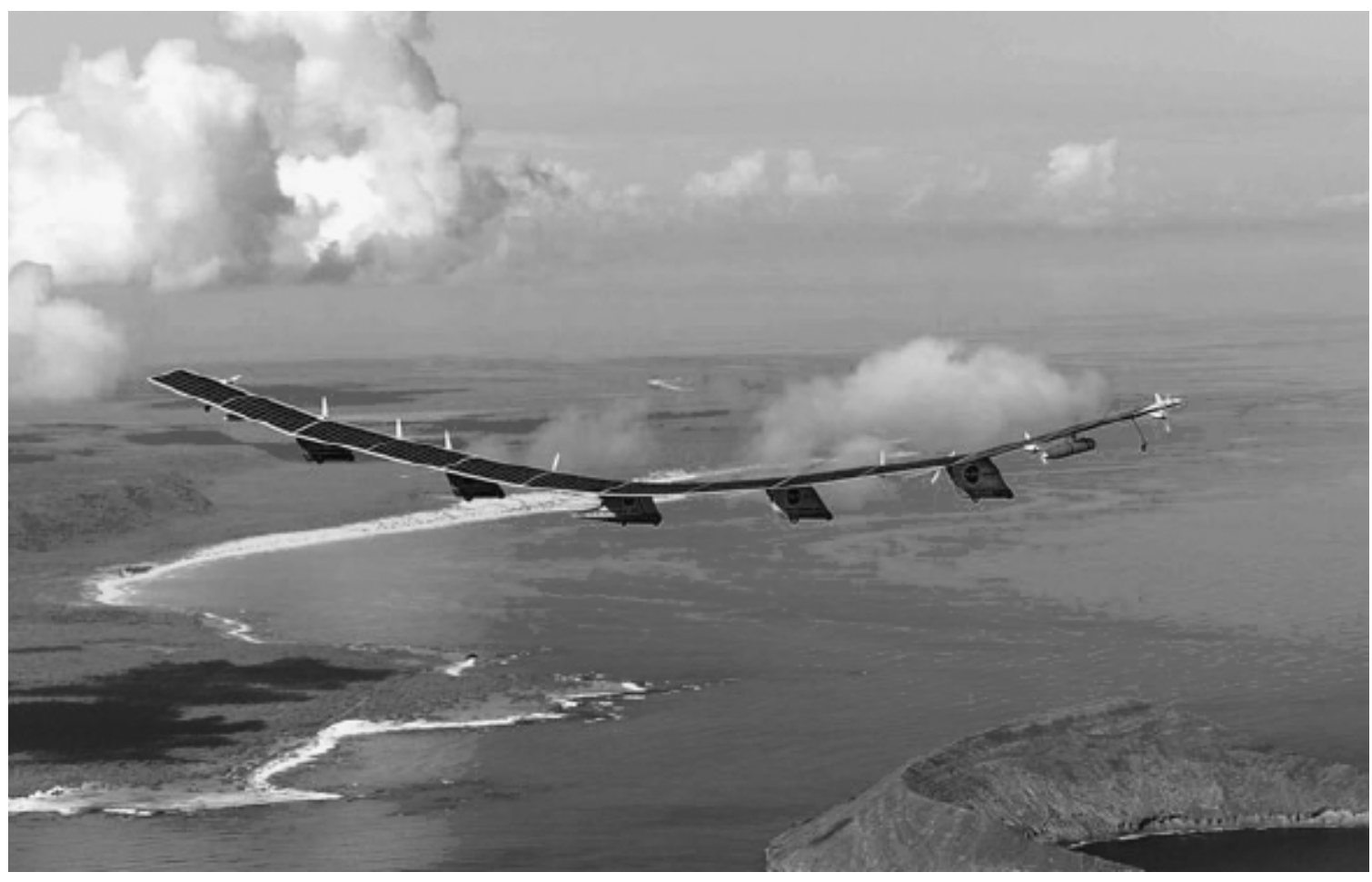

Figure 2: Helios UA. 
the aircraft, and it broke apart. According to the accident report, at least one contributing factor to the accident was the high workload associated with the control handoff procedure. "Approximately 10 minutes prior to the event, the pilot was progressively becoming task-saturated with multiple demands on his attention. This included concurrent concerns with the flight hand-off procedure" (Noll et al., 2004, p. 84).

Yet another instance of a problem with the control handoff occurred during the test of an Altair UA in July 2004. The Altair is a derivative of the Predator B unmanned aircraft. The control station for the Altair normally consists of two pilot stations side by side, which allows control of the aircraft to be transferred from one side to the other during flight. During a flight test, the left pilot console malfunctioned. The crew proceeded to switch control to the right seat pilot console. The switchover took time to accomplish and during that period the aircraft went into its lost-link mode. Uplink was re-established, but as the right seat pilot console came online, the engine shut down. Accounts of the event from observers suggested that the cause of the shutdown was a fuel control switch that was not in the correct position on the right seat console. Fortunately, the pilot used his checklist to perform an engine restart and managed to successfully restart the engine and return to the original altitude (Randy Sundberg, personal communication).

A common theme across most of these reported mishaps is a lack of awareness of system settings on the part of the receiving crew. Sometimes this is because checklists are not properly followed. Other times the displays did not adequately present system status information to the pilot.

\section{Automation}

As UA continue to proliferate, the technology involved with the flight-control system continues to become more and more sophisticated. The ultimate solution seen by many to the problem of flight control of UA is to automate the control. One reason for the tendency to automate is the difficulties experienced by pilots in controlling the aircraft. External pilots have the problems of limited range and inconsistent control mapping, as was discussed earlier. Internal pilots have the problems of delayed control feedback, poor visual imagery, a small field of view, and a general lack of sensory cues (McCarley \& Wickens, 2005). The degree of automation varies a great deal from system to system, with some systems having the capability to be "hand-flown"(e.g., Predator) while other systems have flight control totally automated from takeoff to landing (e.g., Global Hawk).

Accidents involving flight-control automation suggest that it is difficult to anticipate all possible contingencies that can occur during a flight and that even if the automation functions as intended, unintended consequences can occur because of events that are not anticipated. A few examples of unintended consequences will illustrate this point.

The first accident involves the crash of a Navy-owned Vertical Take-off and Landing Tactical Unmanned Aerial Vehicle (VTUAV), called the Fire Scout (see Figure 3).

The investigation of the accident, which occurred on November 4, 2000, revealed that human error associated with damage to onboard antennas during ground handling led to the accident. Because of the damage to the antennas, an incorrect signal was emitted, causing the

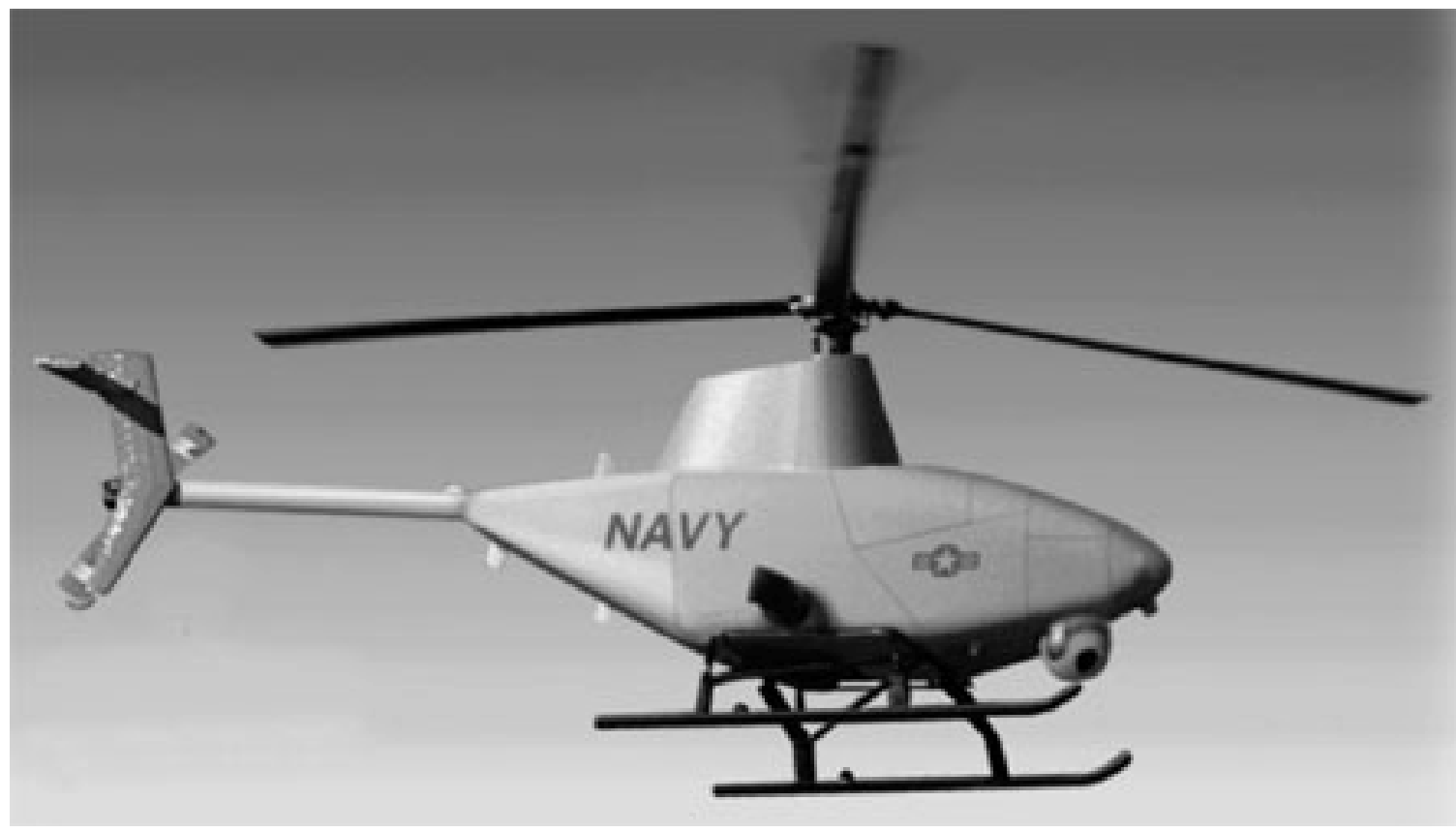

Figure 3. The U.S. Navy Fire Scout (RQ-8A). 
radar altimeter system to incorrectly track the altitude. The antennas gave a false reading that indicated that the Fire Scout was at an altitude of two $\mathrm{ft}$ above the ground when, in fact, it was hovering at an altitude of $500 \mathrm{ft}$ (Strikenet, 2001). After the "land" command was given, the aircraft descended two $\mathrm{ft}$ to $498 \mathrm{ft}$ AGL. The guidance and control system interpreted the incorrect altitude signal as an indication that the Fire Scout had already landed and, performing as designed, shut down the engine. The aircraft quickly lost altitude and crashed.

A mishap of a Global Hawk occurred when the aircraft suffered an inflight problem with temperature regulation of the avionics compartment and landed at a preprogrammed alternate airport for servicing. After landing, the aircraft was commanded to begin taxiing. Unknown to the crew, a taxi speed of 155 knots had been entered into the mission plan at that particular waypoint by the automated mission planning software in use at the time. The mission planning software had been programmed to set the descent speed of the Global Hawk to 155 knots. Any time that two consecutive waypoints varied in altitude by more than a specified amount, the software set the speed to be established between those waypoints at 155 knots. What was not anticipated by the software developers however was two consecutive taxi waypoints on the ground differing by more than the specified amount in altitude. The software, performing as designed, had inserted an airspeed of 155 knots between the waypoints. The aircraft accelerated to the point where it was unable to negotiate a turn and ran off of the runway, collapsing the nose gear and causing extensive damage to the aircraft.

The final example is in regard to the previously mentioned mishap involving the Helios system. After it entered turbulent conditions, the Helios pilot was unable to provide adequate control inputs to avoid the breakup of the aircraft. According to the mishap report, "The pilot's control panel was designed to provide only standard "autopilot type" mode and navigation inputs; it was not designed to provide for direct pilot-in-the-loop control of attitude nor was it designed to provide the pilot [with the] capability to recognize an impending departure from controlled flight or to stabilize the aircraft" (Noll et al., 2004, p.81).

In all of these examples, we see evidence that the developers of the automation were unable to predict all possible contingencies. This led to situations in which the automation performed as designed but not as anticipated.

\section{SUMMARY AND CONCLUSIONS}

In this chapter we have seen examples of three types of UA accident categories. All three categories focus around a type of control problem. External pilot control problems are related to the inconsistent mapping of the control box to the movement of the aircraft. At least two solutions present themselves. The first solution is to design the control box in such a way as to achieve a consistent mapping. Quigley et al. (2004) looked at the use of several options for controlling the aircraft, but all had drawbacks. A second solution is to eliminate the need for an external pilot by automating those portions of flight that currently require an external pilot or by moving the flight control to an internal pilot. Such a solution has been accomplished with several current UA systems. But the use of an internal pilot is affected by factors such as a limited field-of- view, delayed control response and feedback, and a lack of sensory cues. In addition, the implementation of automation presents its own problems. Thus, it cannot be expected to provide a perfect solution.

The problem of transfer of control centers around the fact that the receiver of control is not always fully aware of the status of the system. The problem can be solved by designing the displays in such a way that all critical system parameters are available to the pilot during the transfer. Most research on display design has focused on the task of navigation (e.g., Henry, 2001). Additional research is needed to determine the types of information required during the transfer of control and useful ways to depict that information.

Another method for reducing problems related to transfer of control is a yoked interface between control stations performing a handoff. Basically, the idea consists of establishing a protocol between two control stations (or within stations if the goal is to transfer control from one side to the other) that ensures that all system parameters of the receiving station match those of the sending station. Transfer of the data could be accomplished either through the aircraft data link or directly between the stations as technology permitted.

Automation problems occur because not all circumstances can be predicted. The inability to anticipate all possible contingencies leads to situations in which the system behaves as it was designed but not in a manner that was expected. There are at least two solutions to this problem. The first is to design the system in a way that keeps the pilot more aware of what the aircraft is going to do during the flight. This requirement, of course, assumes that the pilot will also have the ability to intercede in the 
automated task that is being performed. In implementing this solution, we have to deal with what is usually called the "out-of-the-loop" syndrome (Endsley \& Kiris, 1995; Moray, 1986; Wickens \& Hollands, 2000). The out-ofthe-loop syndrome refers to the finding that humans working with automation have a diminished ability to detect system errors and respond to them by performing the task manually.

The second solution to the automation problem is to design the automation to be more flexible so that, even when a particular contingency has not been anticipated, the system is still able to generate an appropriate response. This is a challenge for those developing "intelligent" systems, and this field is still in its infancy.

One conclusion that can be derived from the mishaps presented in this chapter is that flight control of UA is problematic. Understanding the specific issues discussed here should help reduce those accidents. However, as the interfaces of these aircraft continue to evolve, other issues will appear. Much work remains to improve the user interface for UA. New displays, control-interface concepts, and improved automation systems remain to be developed.

\section{REFERENCES}

Endsley, M.R. \& Kiris, E.O. (1995). The out-of-theloop performance problem and level of control in automation. Human Factors, 37(2), 381-94.

Gawron, V.J. (1998). Human factors issues in the development, evaluation, and operation of uninhabited aerial vehicles. AUVSI '98: Proceedings of the Association for Unmanned Vehicle Systems International, Huntsville, AL, 431-8.

Henry, M. (2001). GUI techniques for assessing autonomous vehicle behavior. Air Force Research Laboratory/ HECI Technical Report \#CSC-01-333-F.

Manning, S.D., Rash, C.E., LeDuc, P.A, Noback, R.K., \& McKeon, J. (2004). The role of human causal factors in U.S. Army unmanned aerial vehicle accidents. U.S. Army Aeromedical Research Laboratory Report \# 2004-11.
McCarley, J.S. \& Wickens, C.D. (2005). Human factors implications of UAVs in the national airspace. University of Illinois Institute of Aviation Technical Report (AHFD-05-5/FAA-05-1). Savoy, IL: Aviation Human Factors Division.

Moray, N. (1986). Monitoring behavior and supervisory control. In K. Boff (Ed.), Handbook of perception and human performance (pp. 40/1-51). New York: Wiley.

Noll, T.E., Brown, J.M., Perez-Davis, M.E., Ishmael, S.D., Tiffany, G.C., \& Gaier, M. (2004). Investigation of the Helios prototype aircraft mishap: Volume I, mishap report. Downloaded on 9/2004 from URL www.nasa.gov/pdf/64317main_helios.pdf.

Quigley, M., Goodrich, M.A., \& Beard, R.W. (2004). Semi-autonomous human-UAV interfaces for fixedwing mini-UAVs. Proceedings of IROS 2004, Sep 28 - Oct 2, Sendai, Japan.

Strikenet (2001). VTUAV P1 accident investigation board report. Downloaded on 4/15/2004 from URL www.strikenet.js.mil/pao/vtuav_crash_invest_news_release.html.

U.S. Army (2004). Risk Management Information System Web site. Downloaded on 9/2004 from URL https://safety.army.mil/home.html.

Wickens, C.D., \& Hollands, J.G. (2000). Engineering psychology and human performance (3rd ed.). Atlantic City, NJ: Prentice Hall.

Williams, K.W. (2004). A summary of unmanned aircraft accident/incident data: Human factors implications. Washington, DC: U.S. Department of Transportation, Federal Aviation Administration, Office of Aerospace Medicine. Technical Report Publication No. DOT/FAA/AM-04/24.

Worch, P.R., Borky, J., Gabriel, R., Heiser, W., Swalm, T., \& Wong, T. (1996). United States Air Force Scientific Advisory Board Report on UAV technologies and combat operations. SAB-TR-96-01, Washington, DC: Government Printing Office. 